Check for updates

Cite this: RSC Adv., 2020, 10, 7083

Received 13th November 2019

Accepted 11th February 2020

DOI: $10.1039 / c 9 r a 09464 d$

rsc.li/rsc-advances

\section{Quantitative spatially resolved post-mortem analysis of lithium distribution and transition metal depositions on cycled electrodes via a laser ablation-inductively coupled plasma-optical emission spectrometry method}

\author{
Constantin Lürenbaum, $\uparrow^{\mathrm{a}}$ Britta Vortmann-Westhoven, $\dagger^{\mathrm{a}}$ Marco Evertz, ${ }^{a}$ \\ Martin Winter ${ }^{\mathrm{ab}}$ and Sascha Nowak (D) *a
}

Diminishing the loss of performance of lithium ion batteries (LIBs) is a challenge that is yet to be fulfilled. Understanding of deterioration processes and mechanisms (i.e., so-called aging) requires analytically accurate examination of aged cells. Changes in the distribution of lithium or transition metals in the LIB cells can influence their cycle and calendar life significantly. As electrochemically treated cells and especially their electrodes do not age homogeneously and the local electrochemistry (e.g. deposition patterns) is strongly dependent on surface properties, bulk analysis is not a satisfactory investigation method. Therefore, a surface sensitive method, namely laser ablation-inductively coupled plasma-optical emission spectrometry (LA-ICP-OES) is presented. LIB cells with lithium metal oxide $\mathrm{LiNi}_{1 / 3} \mathrm{Co}_{1 / 3} \mathrm{Mn}_{1 / 3} \mathrm{O}_{2}$ (NCM111) as cathode material and graphite as anode material are investigated using a $213 \mathrm{~nm} \mathrm{Nd:YAG} \mathrm{laser.}$

\section{Introduction}

Electric vehicles, hybrid electric vehicles (xEVs), portable electronic devices and stationary energy storage systems are the main applications of high energy, high power and high energy efficiency lithium-ion batteries (LIBs). ${ }^{1-4}$ The positive electrode (cathode) is most commonly comprised of layered lithium transition metal oxides $\left(\mathrm{LiMO}_{2}, \mathrm{M}=\mathrm{Ni}, \mathrm{Co}, \mathrm{Mn}\right)$ with practical discharge capacities of $150-220 \mathrm{~mA} \mathrm{~h} \mathrm{~g}{ }^{-1.5}$ The negative electrode (anode) is based on carbonaceous materials (mostly graphite) featuring decent theoretical capacities of $372 \mathrm{~mA} \mathrm{~h} \mathrm{~g}{ }^{-1} \cdot{ }^{6-11} \mathrm{~A}$ separator which is soaked with electrolyte inhibits direct contact of the electrodes. ${ }^{12}$ The electrolyte formulation usually consists of $1 \mathrm{M} \mathrm{LiPF}_{6}$ dissolved in a mixture of linear and cyclic organic carbonates. ${ }^{13-19}$ One of the main challenges for consumer acceptance of LIBs is their limited cycle and calendar life. Unwanted interactions and interreactions of the cell components are closely related to the degradation (=aging) of the battery cell components. ${ }^{20-37}$ One of the most renowned aging processes is the formation of the solid electrolyte interphase (SEI) on the anode surface due to the reductive operation potentials. $^{38,39}$ Furthermore, during

${ }^{a}$ MEET Battery Research Center, University of Münster, Corrensstraße 46, 48149 Münster, Germany.E-mail: sascha.nowak@uni-muenster.de

${ }^{b}$ Helmholtz Institute Münster, IEK-12, Forschungszentrum Jülich GmbH, Corrensstraße 46, 48149 Münster, Germany

$\dagger$ The authors contribute equally to this paper. operation of the cell the continuous growth of the SEI consumes active lithium, thus, leading to a steady capacity loss. ${ }^{40-42}$ Another aging phenomenon is the transition metal dissolution (TMD) of the cathode, which can harm the SEI due to transition metal deposition on the surface, leading to deterioration and restructuring of the SEI layer. ${ }^{6,22,43-46}$

Imaging techniques are inevitably needed to examine TMD and the lithium loss in the field of LIBs, both in a quantitative and spatially resolved manner. Common techniques include scanning electron microscopy (SEM) with energy dispersive X-ray analysis (EDX) or transmission electron microscopy (TEM) to discover surfaces and their changes. ${ }^{4-50}$ Furthermore, Aurbach et al. introduced atomic force microscopy (AFM) and Chandrashekar et al. established ${ }^{7} \mathrm{Li}$ magnetic resonance imaging (MRI).51,52 Other applied surface analysis techniques are X-ray photoelectron spectroscopy (XPS) and secondary ion mass spectrometry (SIMS).$^{6,37,53,54}$ However, all these techniques suffer from their inability to obtain quantitative results, or at least have huge obstacles to overcome (e.g., SIMS or XPS). ${ }^{37}$ Additionally, the limitation to small spot sizes (in the range of mid- $\mu \mathrm{m}$ ) display another disadvantage from a statistical point of view. In comparison to the above mentioned methods, laser ablation (LA) coupled to an elemental analysis technique, such as inductively coupled plasma (either with mass or optical detection) provides both a good lateral resolution of several ten micrometer and a depth resolution which is just above the size of the active material particles, i.e. below one micrometer. Furthermore, it is possible to investigate whole electrodes with a diameter of several 


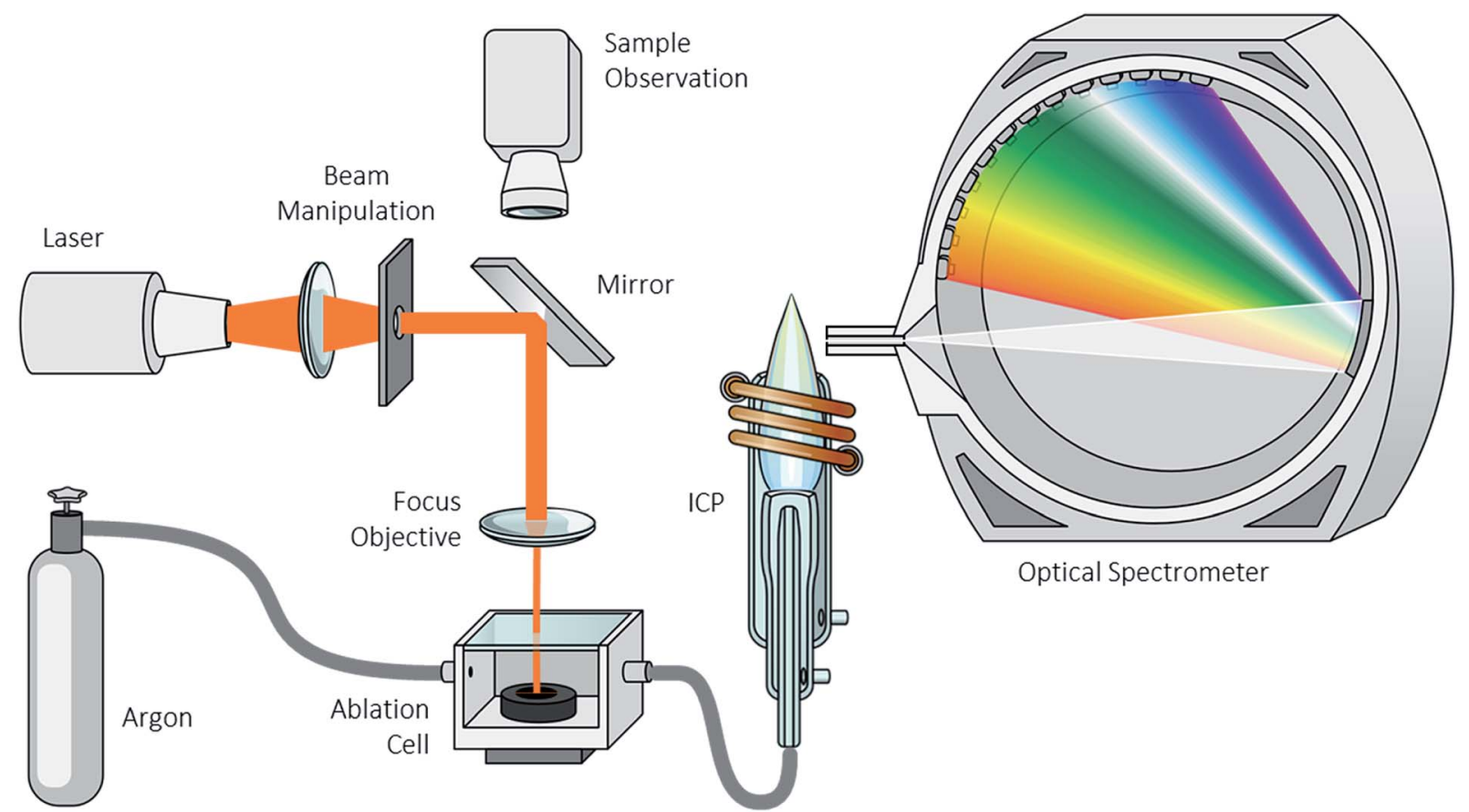

Fig. 1 Schematic set-up of the LA-ICP-OES system.

millimeter or even bigger samples. LA-ICP-MS coupling is a wellknown technique in the field of geology or clinical tissue analysis, though, not widely adapted in the battery context. ${ }^{55-60}$ Despite being less established than LA-ICP-MS, LA coupled to inductively coupled plasma-optical emission spectrometry (LA-ICP-OES) has been applied for microanalysis. ${ }^{61-65}$

In this work, we show an approach for a complete ablation of electrochemically aged LIB cells via quantitative imaging analysis using LA-ICP-OES to spatially resolve the lithium distribution on carbonaceous anodes as well as deposition patterns of the respective transition metals.

\section{Experimental}

\section{Cell materials}

Lithium nickel cobalt manganese oxide $\left(\mathrm{LiNi}_{1 / 3} \mathrm{Co}_{1 / 3} \mathrm{Mn}_{1 / 3} \mathrm{O}_{2}\right.$, NCM111) and mesocarbon microbeads (MCMB) graphite electrodes were obtained from Evonik Litarion (Kamenz, Germany).

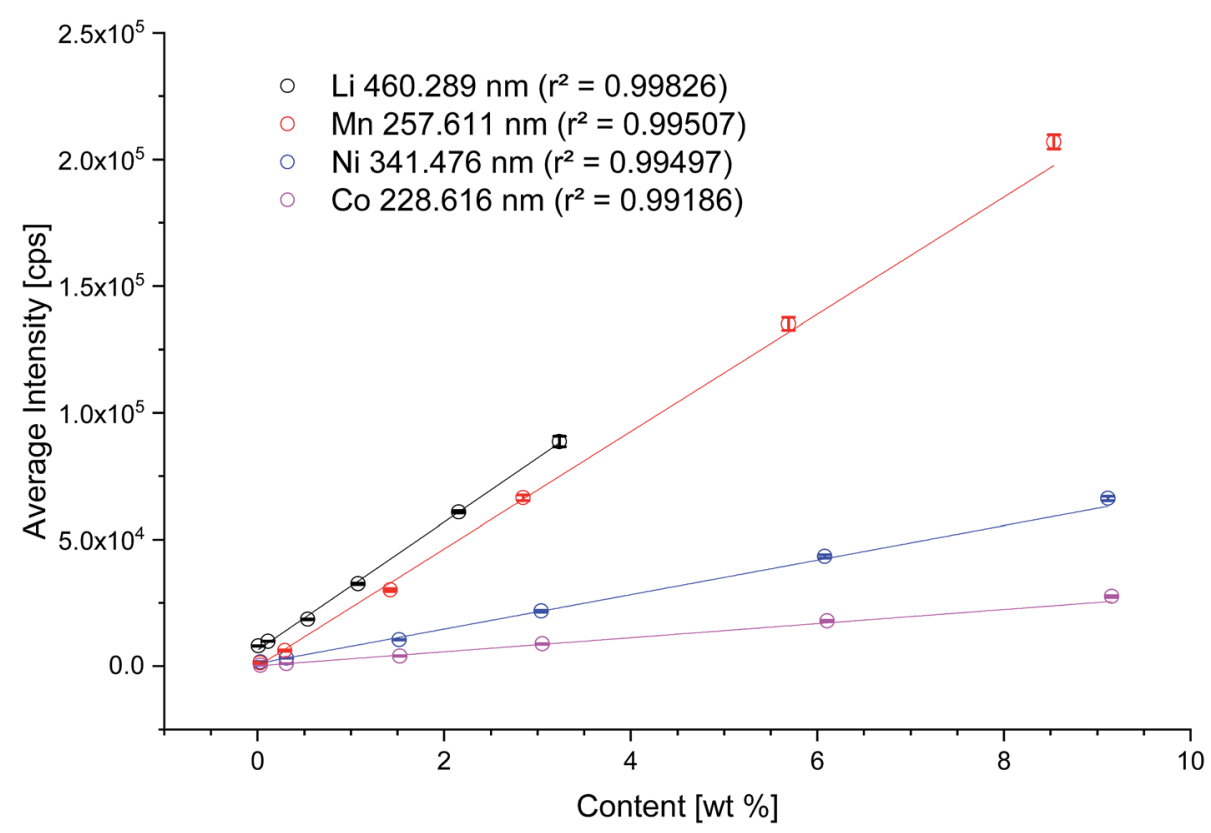

Fig. 2 Calibration of the LA-ICP-OES system with matrix-matched standards for the elements Li (black), Mn (red), Ni (blue), Co (magenta). 
Table $1 \mathrm{LOD} / \mathrm{LOQ}$ in wt\% with relative standard deviations for LAICP-OES examination for transition metals depositions on electrodes

\begin{tabular}{lllll}
\hline & $\mathrm{Li}_{460 \mathrm{~nm}}$ & $\mathrm{Ni}_{341 \mathrm{~nm}}$ & $\mathrm{Co}_{227 \mathrm{~nm}}$ & $\mathrm{Mn}_{258 \mathrm{~nm}}$ \\
\hline LOD (wt\%) & 0.03 & 0.08 & 0.13 & 0.08 \\
LOQ (wt\%) & 0.16 & 0.28 & 0.44 & 0.27 \\
rStdv (\%) & 1.7 & 3.2 & 3.2 & 4.0 \\
\hline
\end{tabular}

The separator Celgard ${ }^{\circledR} 2500$ was obtained from Celgard (North Carolina, USA). Battery grade electrolyte LP30 SelectiLyte ${ }^{\mathrm{TM}}$ $\left(1 \mathrm{~mol} \mathrm{~L}^{-1} \mathrm{LiPF}_{6}\right.$ in ethylene carbonate (EC) and dimethyl carbonate (DMC) $(1: 1, \mathrm{w} / \mathrm{w}))$ and DMC SelectiLyte ${ }^{\mathrm{TM}}$ were purchased from BASF (Ludwigshafen, Germany). The pouch bag foil was ordered from SOLE Caldo di G. Ciocci (Tivoli, RM, Italy). Argon (purity 4.8) was obtained from Westfalen Gas (Münster, Germany).

\section{Matrix-matched standards}

Matrix-matched standards were prepared using MCMB graphite/ hard carbon composite (MTI Corporation, USA/SGL Group Meitingen, Germany) as carbonaceous source for the negative electrode and increasing contents of NCM111 (Custom Cells Hamburg, Germany) as source for cobalt, nickel, manganese and lithium. For the preparation of the matrix-matched standards the procedure described by Evertz et al. was adapted in this work. ${ }^{66}$ The slurries were prepared using polyvinylidene difluoride (PVdF, Solvay Solexis Tavaux, France) as binder dissolved in $N$-methyl-2pyrrolidone (NMP, 99.5\%, Acros Organics). Furthermore, conductive carbon (SuperP®, 99.7\%, Imerys) was added to the slurry.

\section{Cell preparation and cycling conditions}

For charge/discharge aging investigations, the cells were assembled using NCM111 as positive electrode

b)

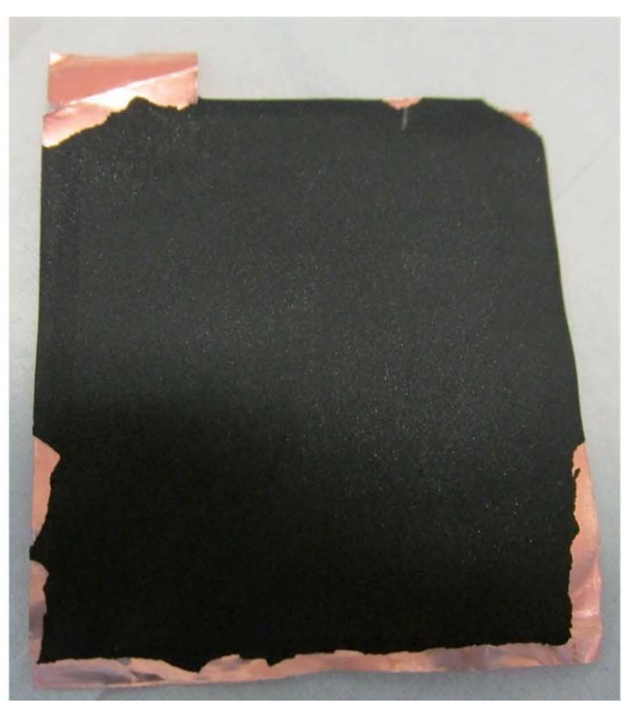

d)

c)

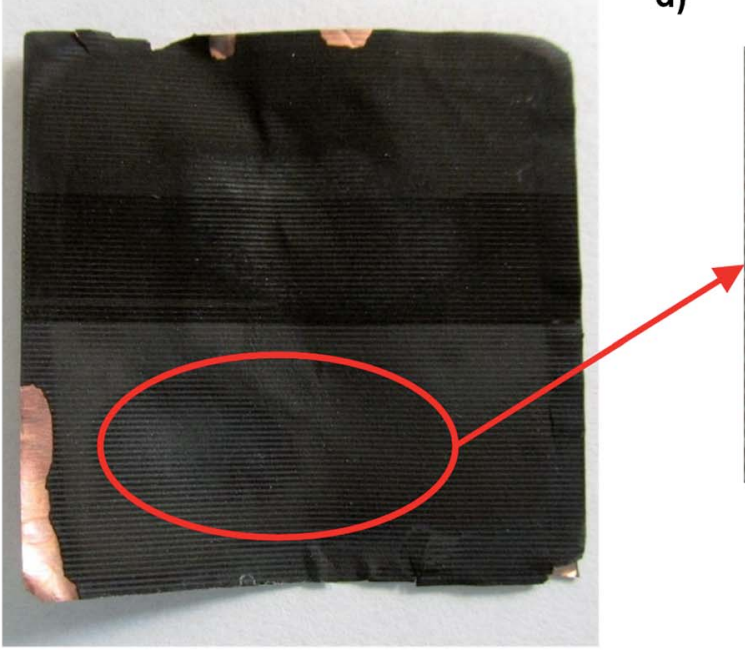

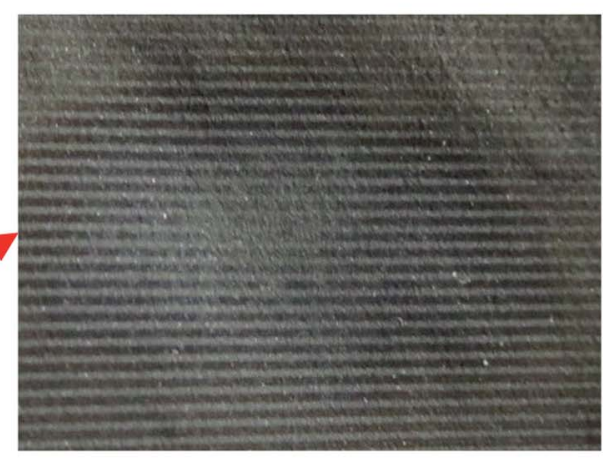

Fig. 3 Images of the graphitic anodes: (a) pristine anode, (b) cycled anode A, (c) cycled anode B, area of interest (highlighted in red) after the ablation process. (d) Zoomed-in image of the impurity after ablation. 
(2.22 $\mathrm{mA} \mathrm{h} \mathrm{cm}^{-2}, 93 \%$ active material, $\left.A=9.0 \mathrm{~cm}^{2}\right)$ and MCMB as negative electrode $\left(2.86 \mathrm{~mA} \mathrm{~h} \mathrm{~cm}{ }^{-2}, 91 \%\right.$ active material, $A=$ $10.9 \mathrm{~cm}^{2}$ ). As separator, Celgard $\AA 2500$ soaked with $160 \mu \mathrm{L} \mathrm{LP} 30$ electrolyte were used. After a rest step of $24 \mathrm{~h}$, the cells were cycled at $40{ }^{\circ} \mathrm{C}$ using a Maccor Series 4000 battery tester (Tulsa, USA). The cycling procedure consisted of a constant current/ constant voltage (CCCV) charge step followed by a constant current (CC) discharge. After five formation cycles with charge and discharge rates of $\mathrm{C} / 10\left(15 \mathrm{~mA} \mathrm{~g}^{-1}\right), 100$ cycles were performed with a charge rate of $1 \mathrm{C}\left(150 \mathrm{~mA} \mathrm{~g}^{-1}\right)$ in a cell voltage window from $2.5 \mathrm{~V}$ to $4.2 \mathrm{~V}$ and a constant voltage step until the current came below $\mathrm{C} / 20\left(7.5 \mathrm{~mA} \mathrm{~g}^{-1}\right)$. After cycling, the pouch bag cells were opened in an argon-filled glove box $\left(\mathrm{H}_{2} \mathrm{O}<\right.$ $0.1 \mathrm{ppm}$ and $\left.\mathrm{O}_{2}<0.1 \mathrm{ppm}\right)$ to prevent contact with air and moisture. The MCMB electrodes were rinsed with $2 \mathrm{~mL}$ of DMC and dried overnight in an argon atmosphere.

\section{LA-ICP-OES conditions}

The LSX-213 laser ablation system from Teledyne CETAC (Omaha, NE, USA) was coupled to an ICP-OES instrument including a lateral plasma viewing from Spectro Analytical Instruments (Spectro ARCOS ICP-OES, Kleve, Germany). The LA system was controlled by the software DigiLaz III (version 3.2.3, Teledyne CETAC, Omaha, NE, USA). The software Smart Analyzer Vision (version 5.01.0927, Spectro Analytical Instruments, Kleve, Germany) controlled the ICP-OES system (Fig. 1). The investigations were carried out with a laser energy of $25 \%(\sim 1$ $\mathrm{mJ}$ ), a frequency of $10 \mathrm{~Hz}$, a scan rate of $50 \mu \mathrm{m} \mathrm{s}^{-1}$ and a spot size of $150 \mu \mathrm{m}$ with a line spacing of $150 \mu \mathrm{m}$. Argon was used as the carrier gas. The transient measurements were carried out with a standard Fassel-type torch with an inner diameter of $1.8 \mathrm{~mm}$. Furthermore, an RF power of $1050 \mathrm{~W}$, a total argon flow of 14.2 $\mathrm{L} \min ^{-1}$ (nebulizer gas: $0.7 \mathrm{~L} \mathrm{~min}{ }^{-1}$, auxiliary gas: $1.5 \mathrm{~L} \mathrm{~min}^{-1}$ and cooling gas: 12.0 $\mathrm{L} \mathrm{min}^{-1}$ ), a frequency of $10 \mathrm{~Hz}$ and an integration interval of $100 \mathrm{~ms}$ were applied. The selected wavelengths were $460.289 \mathrm{~nm}$ for lithium, $341.476 \mathrm{~nm}$ for nickel, $257.611 \mathrm{~nm}$ for manganese and $228.616 \mathrm{~nm}$ for cobalt. The transient data was analyzed using the program Origin 9.1.

\section{Results and discussion}

In Fig. 2, the results for the calibration of the matrix-matched standards are depicted. For all recorded emission lines, the correlation coefficient is higher than 0.99 , showing the applicability of the standards. Instead of the most intensive $\mathrm{Li}$ emission line of $670.870 \mathrm{~nm}$, the emission line at $460.289 \mathrm{~nm}$ with a lower intensity was selected as the obtained signal for $670.870 \mathrm{~nm}$ was already above the working range of the detector. For the determination of the detection limit and limit of quantification (LOD and LOQ), five lines of a standard material were ablated. By using the average intensity of five ablated lines of standard material, the influence of variation in

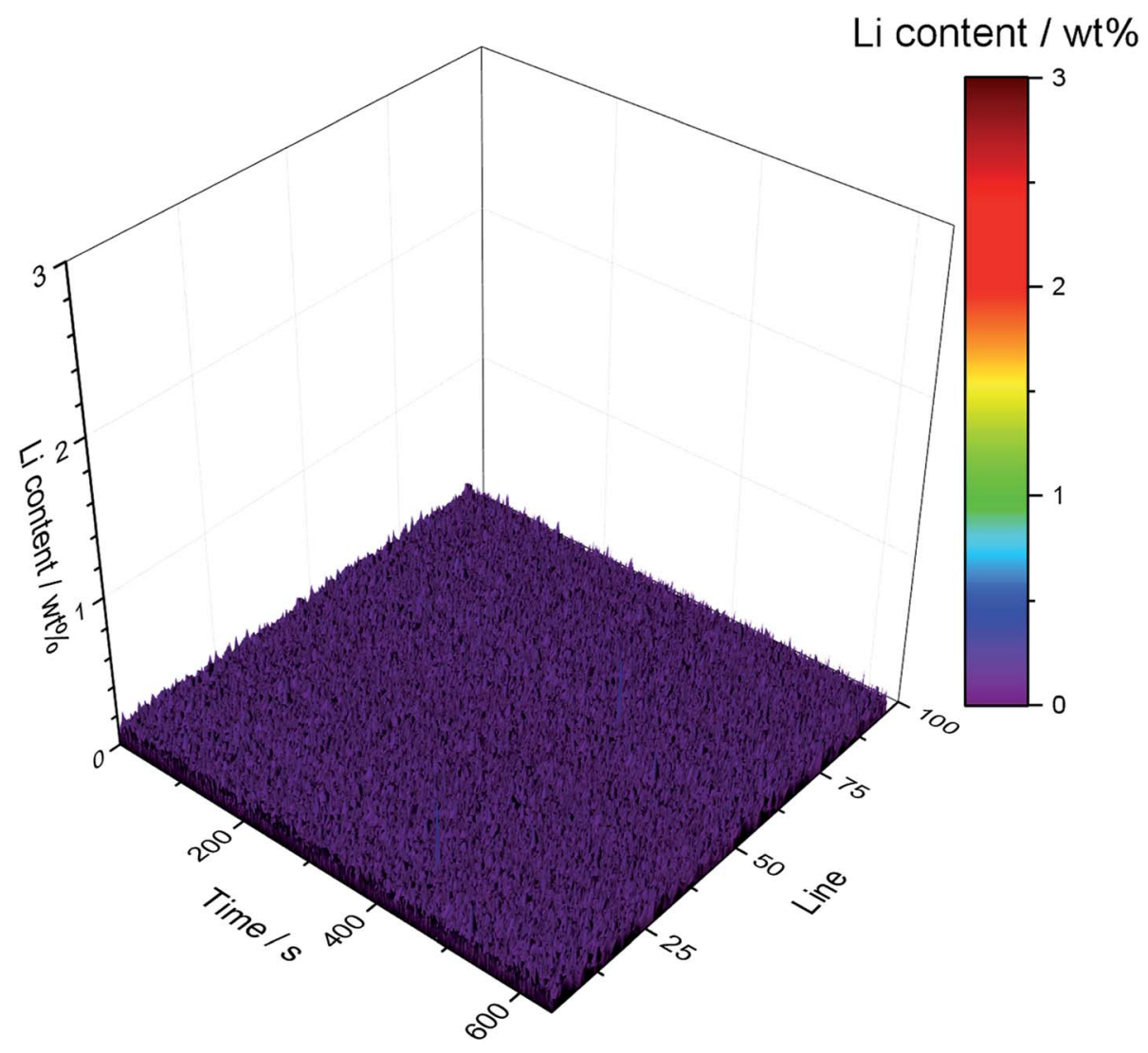

Fig. 4 Lithium distribution of the completely ablated pristine anode. 
the ablation depths is minimized. Based on the 3- and 10-sigma criteria, the LOD and LOQ were calculated (Table 1):

The highest lithium concentration of $3 \mathrm{wt} \%$ is calculated with NCM111, thus the highest standard for $\mathrm{Ni}$ is $8.6 \mathrm{wt} \%$, for Co $8.7 \mathrm{wt} \%$ and for Mn $8.1 \mathrm{wt} \%$, respectively. Charge/discharge aged electrodes were investigated by ablating the whole surface area of the electrodes $\left(33 \mathrm{~mm} \times 33 \mathrm{~mm}, 1089 \mathrm{~mm}^{2}\right)$. The preparation of standards, in the sense of matrix matched, is limited to a reasonable amount of NCM. The highest amount of NCM for graphitic anodes was set to $3 \mathrm{wt} \%$.

Some of the results are subject of extrapolation as the measured signals are above the calibration and no matrixmatched standards are accessible for such high concentrations. Therefore, the calibration is extrapolated based on the assumption of a linear relationship between $\mathrm{wt} \%$ and signal intensity.

Three pouch-bag cells were assembled, two were cycled at $40{ }^{\circ} \mathrm{C}$, one was applied for reference. After disassembly, the anodes were analyzed (pristine anode, cycled anode A and B, see Fig. 3). An image of the pristine anode is given in Fig. 3a, showing a smooth surface with no defects. In comparison, the optical assessment of the cycled anode A shows a blank copper current collector at the edges (Fig. 3b). After cycling and during the disassembly of the anode from the pouch-bag cell, the active material had flaked off at the edges, probably due to increased brittleness of the electrode after aging as the graphite anode material underwent volume changes of up to $\approx 10 \%$ in each cycle. ${ }^{67}$ Anode B exhibits brighter spots in the images (see Fig. 3c (red cycle) and Fig. 3d (enhanced view)). This can possibly be attributed to either lithium plating (metallic lithium deposition) induced by local inhomogeneities (i.e. higher local currents) or by an induced short circuit due to dendrite growth leading to direct contact of the electrodes. These are regions of interest for subsequent investigations.

An elemental mapping of the lithium content of the pristine anode quantified via LA-ICP-OES is shown in Fig. 4. No lithium signal and no transition metal signals could be detected; the intensities are below the respective LODs (0.03 wt\%, 8000 cps) of the developed method.

Focusing on the depositions of the analytes of interest, Fig. 5 shows the results of an ablation of electrochemically aged carbonaceous anodes. Lithium (Fig. 5a) is distributed homogenously on the surface of the electrode, however, an accumulation of lithium can be detected in the first 25 ablation lines. a)

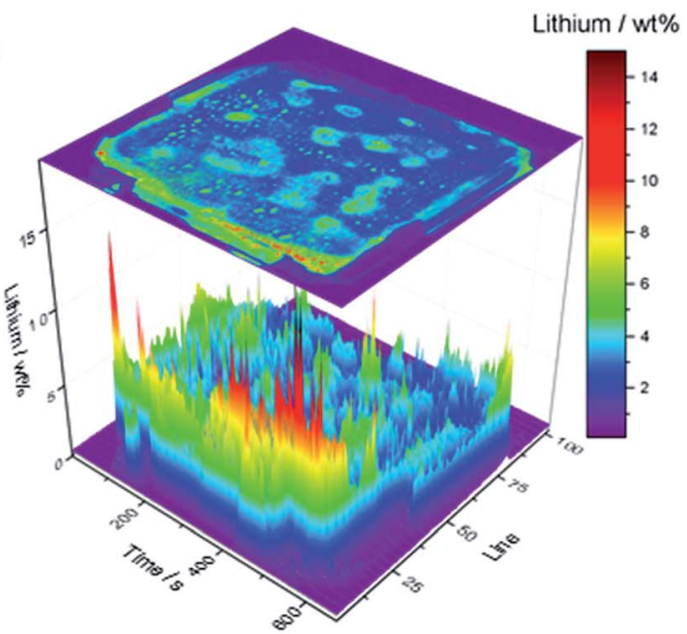

c)

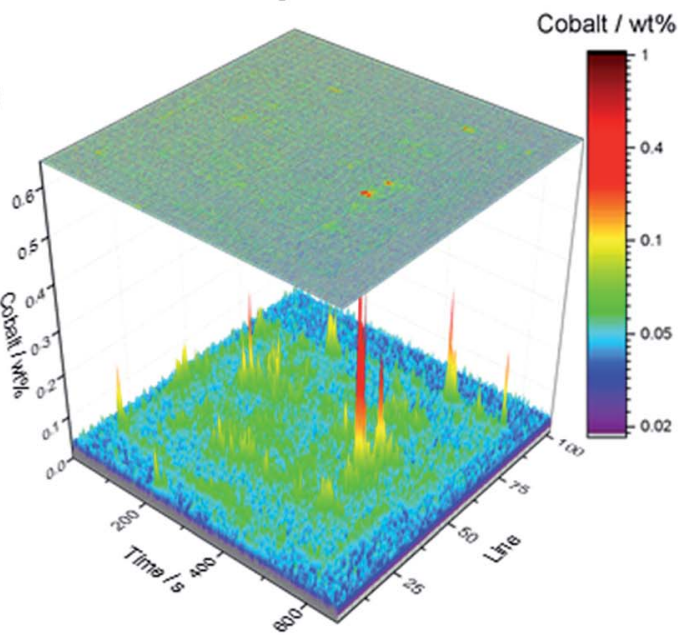

b)

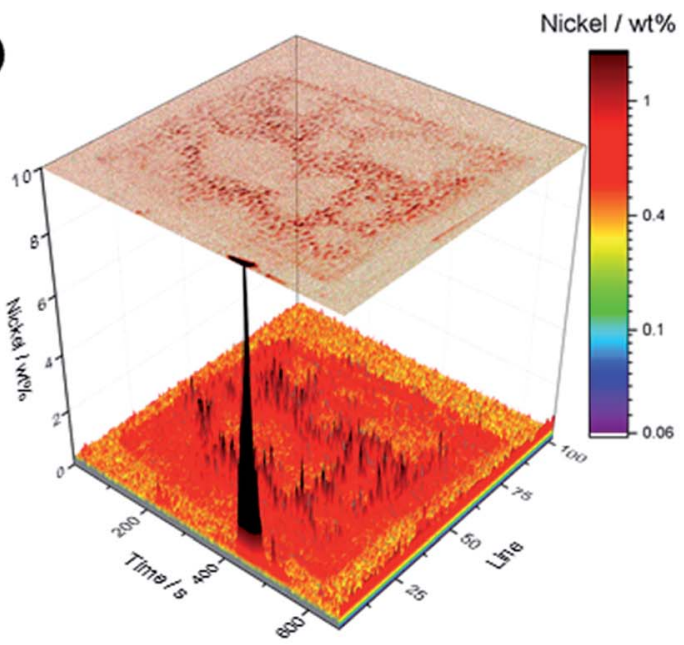

d)

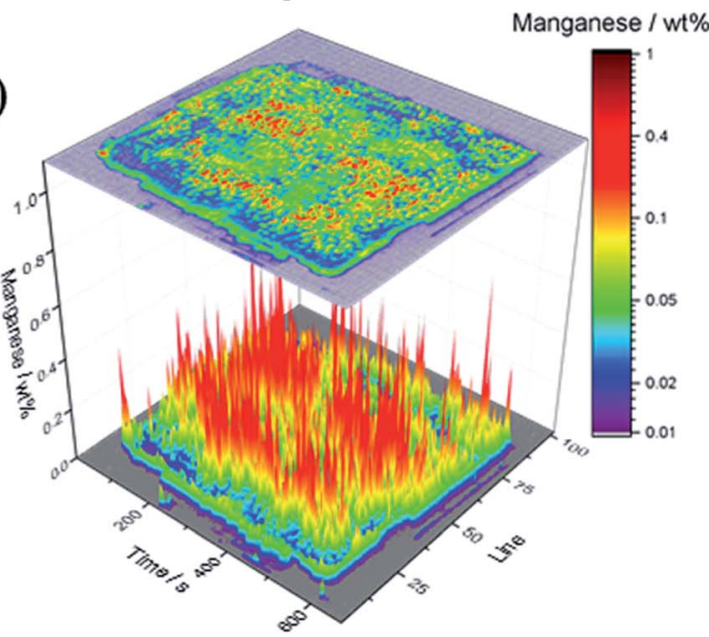

Fig. 5 Quantitative results of the ablated graphitic anode A; concentration is depicted in wt\%; (a) lithium, (b) nickel, (c) cobalt and (d) manganese. 
a)

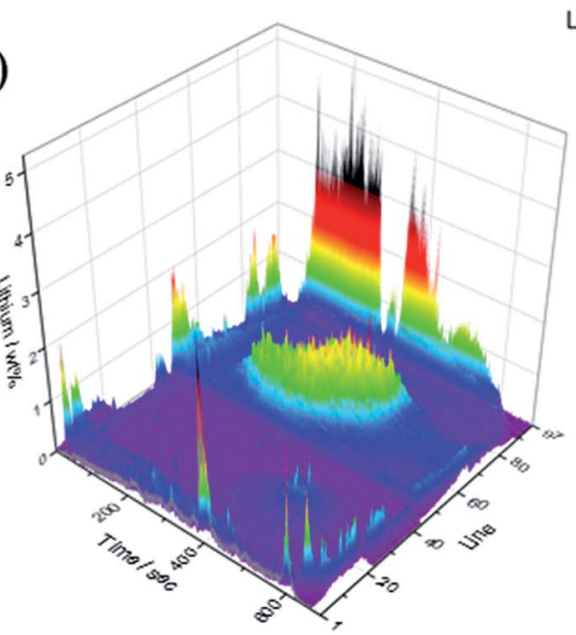

b)

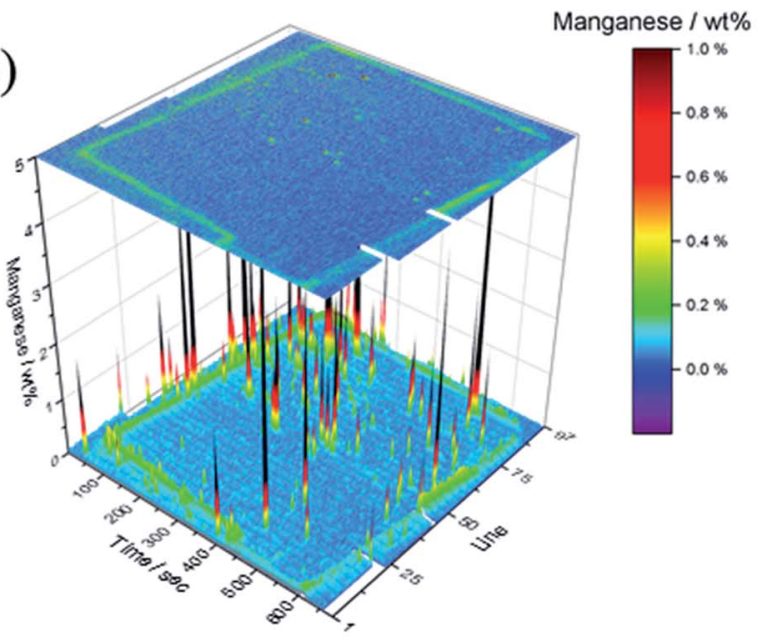

hium / wt\%

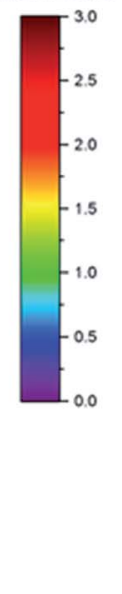

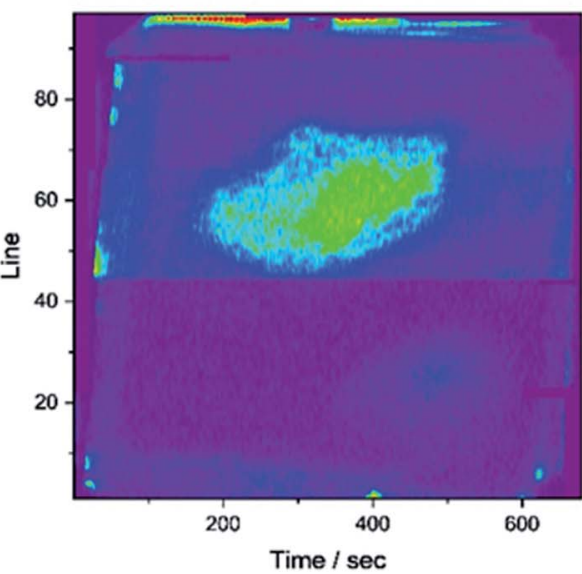

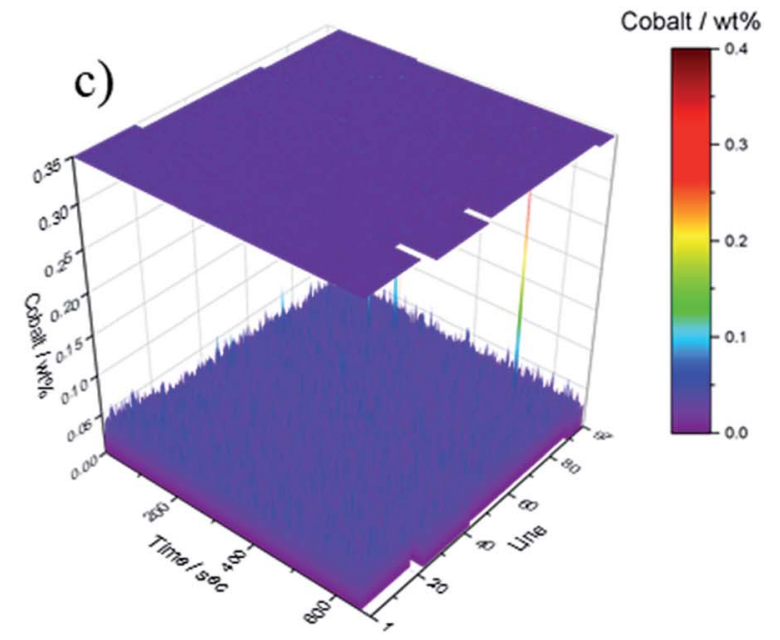

Nickel / wt\%

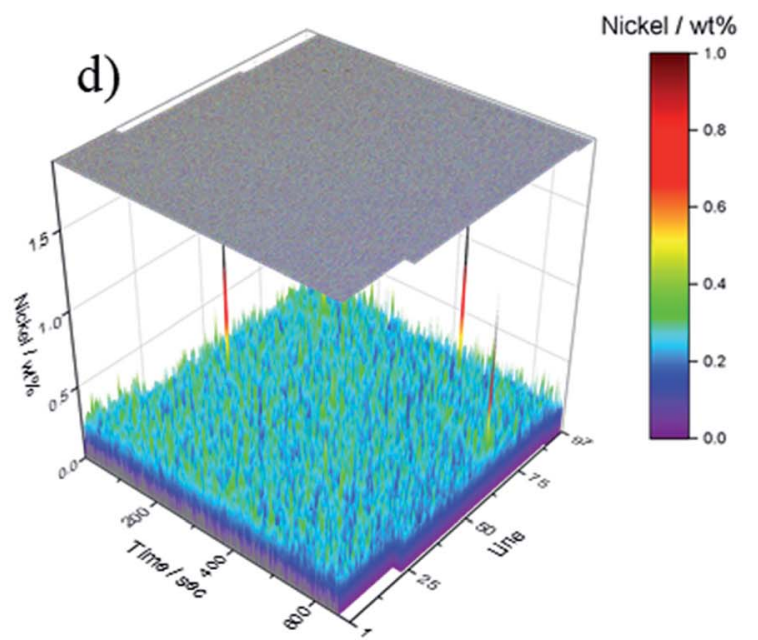

Fig. 6 Quantitative LA-ICP-OES results of the ablated graphitic anode B; data is depicted in wt\%; (a) lithium, (b) manganese, (c) cobalt and (d) nickel.

This may be attributed to a locally increased current density as the current collector tabs are located on this side of the electrode. Additionally, the flaking of the active material from the current collector can be another reason for this accumulation (cf. Fig. 3). The average concentration of the lithium depositions is in the range of $2.5 \mathrm{wt} \%$ except for higher concentration near the current collector tabs. However, due to the necessary extrapolation of the calibration curve, no linear correlation can 

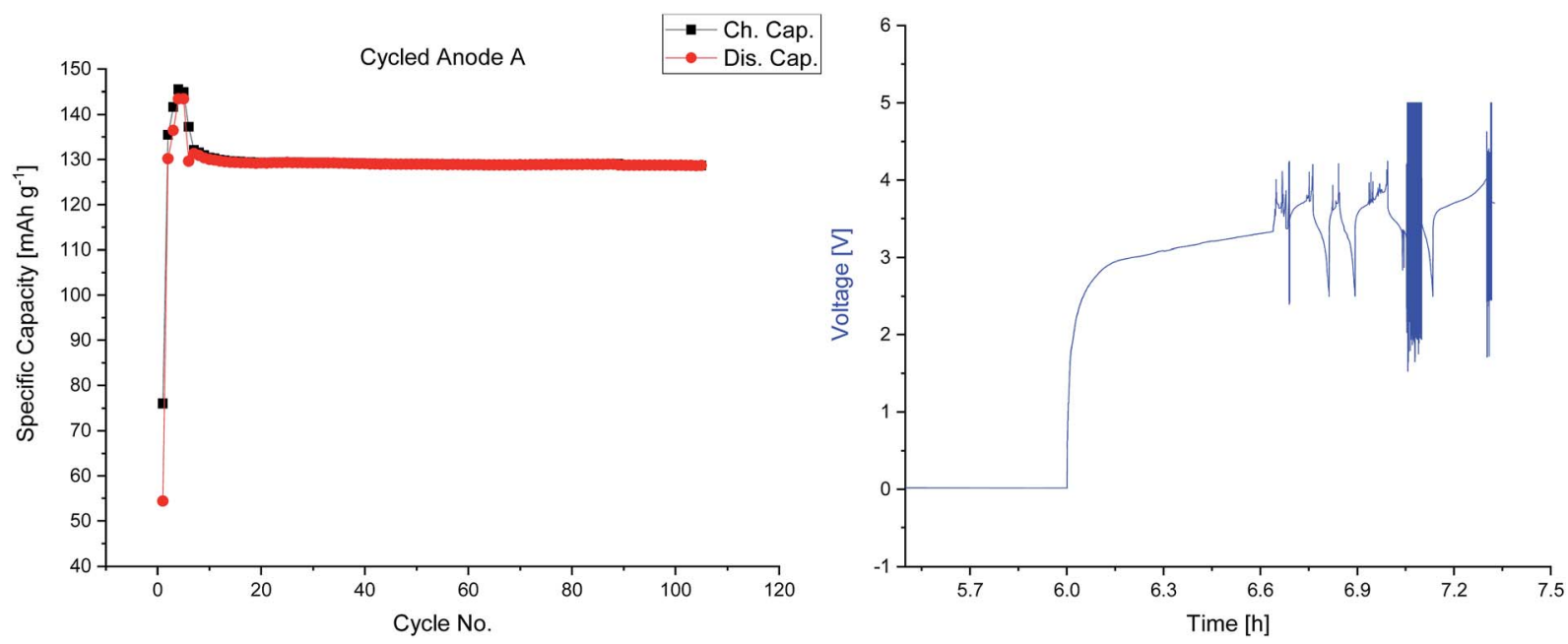

Fig. 7 Charge and discharge capacities versus cycle numbers of cell A (anode A) and voltage profile of the defective cell B (anode B).

be guaranteed, which may lead to inaccurate quantification results. All results represent the first $\mu \mathrm{m}$ of the electrode thickness and thus are closely related to the analysis of the protective SEI layer.

The quantitative analysis for the transition metals is shown in Fig. $5 \mathrm{~b}-\mathrm{d}$ and yielded concentrations in the range between $0.1 \mathrm{wt} \%$ and $0.5 \mathrm{wt} \%$. These values are significantly higher, as previously reported in literature. ${ }^{43,44}$ Cobalt deposition is suppressed which is in agreement with the literature. ${ }^{40}$ Furthermore, manganese deposition is promoted on the carbonaceous anodes compared to the nickel and cobalt deposition. Evertz et al. showed this behavior for NCM111 electrodes treated in a similar way and concluded that the manganese ion movement in the electrostatic field is predominant which was explained by a stagnating concentration of manganese in electrolyte solutions after a specific electrochemically aging duration. ${ }^{43,44}$

In Fig. 5b, the nickel concentration is the highest at the current collector tabs; again, this can be explained by high local current densities.

The spatially resolved illustration of the lithium distribution on the anode B is presented in Fig. 6a. The electrochemical data of cell B (Fig. 7) indicates a failure of the cell at $\approx 40 \mathrm{~min}$ of charging in the formation step; all subsequent cycles were performed within one hour. In order to examine the reason for this cycling behavior, the cell was analyzed analog to anode A. In contrast to Fig. 5a, the lithium distribution in Fig. 6a differs significantly as no spatial homogeneity can be detected. Moreover, Fig. 6a shows two regions of interest - the central region of the anode B (200-500 s, lines 45-75) as well as at the lower edge of the electrode $(60-520 \mathrm{~s}$, lines 94-96). The increased $\mathrm{Li}$ contents could be an indicator for Li plating. However, further examinations, using other techniques (e.g. solid state NMR or scanning electron microscopy) are necessary in order to confirm this assumption. The observations on the optical images $(c f$. Fig. $3 \mathrm{c}$ and d) are matching the regions in the LA-ICP-OES image (Fig. 6a). Focusing on the transition metal deposition on the anode of cell B, a similar deposition pattern for all TMs can be detected despite the high lithium deposition. The deposited amounts of nickel and cobalt are lower than those of manganese, however, the depositions of nickel and cobalt are distributed homogenously over the whole surface of the anode. Nevertheless, compared to the depositions on anode A the concentrations are lower. This could be explained by the shorter duration of the electrochemical aging. Manganese shows an inhomogeneous deposition, which is visualized in Fig. 6b (black peaks), however, the overall amount of manganese deposition is lower than for anode A ( $c f$. Fig. 5d). Furthermore, the edges of the corresponding cathode and current collector tabs are resolved nicely in this spatially resolved image (Fig. 6b). Overall, with these analytical findings it is possible to make a statement about the lithium and TM distribution on graphitic anodes.

\section{Conclusions}

In this work, the spatially-resolved quantitative analysis of lithium, nickel, cobalt and manganese on cycled anodes by LAICP-OES was successfully applied for the post-mortem examination of LIB electrodes. The quantification was performed by using self-prepared matrix-matched standards; correlation coefficients higher than $r^{2}=0.99$ could be achieved with reasonably low standard deviations. The investigation of electrochemically treated carbonaceous anodes revealed a homogeneous lithium distribution on electrochemically aged electrodes. The measured TM contents are significantly higher than previously reported. This can likely be explained by measurement inaccuracies, as no correction for varying ablation yields or fractionation effects (such as transport efficiencies) was applied. In order to improve the precision of this method, possible internal standards need to be evaluated and applied.

Furthermore, the amounts and distribution of transition metal deposition could be analyzed using the LA-ICP-OES setup, and revealing homogenous distribution of all three investigated transition metals (manganese, cobalt and nickel). Additionally, 
the pronounced manganese deposition on carbonaceous anodes could be confirmed in accordance to literature. ${ }^{45}$ Moreover, the local deposition of lithium in a defective LIB cell could be visualized.

In principle, this method can be applied for the study of other transition metal-based cathodes. For the analysis of other graphitic anodes, specifically adjusted matrix matched standards and adjusted parameters for the LA are required.

\section{Conflicts of interest}

There are no conflicts to declare.

\section{Acknowledgements}

The authors wish to thank the German Federal Ministry for Economic Affairs and Energy (BMWi) for funding the project 'TRFA-KAL' (03TNH009D).

\section{References}

1 M. Winter, B. Barnett and K. Xu, Chem. Rev., 2018, 118, 11433-11456.

2 G. Pistoia and B. Liaw, Behaviour of Lithium-Ion Batteries in Electric Vehicles: Battery Health, Performance, Safety, and Cost, Springer, 2018.

3 R. Schmuch, R. Wagner, G. Hörpel, T. Placke and M. Winter, Nat. Energy, 2018, 3, 267.

4 P. Meister, H. Jia, J. Li, R. Kloepsch, M. Winter and T. Placke, Chem. Mater., 2016, 28, 7203-7217.

5 R. Wagner, N. Preschitschek, S. Passerini, J. Leker and M. Winter, J. Appl. Electrochem., 2013, 43, 481-496.

6 D. P. Abraham, T. Spila, M. M. Furczon and E. Sammann, Electrochem. Solid-State Lett., 2008, 11, A226-A228.

7 J. O. Besenhard, M. Winter, J. Yang and W. Biberacher, J. Power Sources, 1995, 54, 228-231.

8 H. Buqa, R. Blyth, P. Golob, B. Evers, I. Schneider, M. S. Alvarez, F. Hofer, F. Netzer, M. Ramsey and M. Winter, Ionics, 2000, 6, 172-179.

9 M. Winter and J. O. Besenhard, Handbook of battery materials, 1999, pp. 383-418.

10 M. Winter, J. O. Besenhard, M. E. Spahr and P. Novák, Adv. Mater., 1998, 10, 725-763.

11 M. Winter, K.-C. Moeller and J. O. Besenhard, in Lithium Batteries: Science and Technology, ed. G.-A. Nazri and G. Pistoia, Springer US, Boston, MA, 2003, pp. 145-194.

12 S. S. Zhang, J. Power Sources, 2007, 164, 351-364.

13 K. C. Möller, T. Hodal, W. K. Appel, M. Winter and J. O. Besenhard, J. Power Sources, 2001, 97-98, 595-597.

14 R. W. Schmitz, P. Murmann, R. Schmitz, R. Müller, L. Krämer, J. Kasnatscheew, P. Isken, P. Niehoff, S. Nowak, G.-V. Röschenthaler, N. Ignatiev, P. Sartori, S. Passerini, M. Kunze, A. Lex-Balducci, C. Schreiner, I. Cekic-Laskovic and M. Winter, Prog. Solid State Chem., 2014, 42, 65-84.

15 D. Aurbach, Y. Ein-Eli, B. Markovsky, A. Zaban, S. Luski, Y. Carmeli and H. Yamin, J. Electrochem. Soc., 1995, 142, 2882-2890.
16 D. Aurbach, K. Gamolsky, B. Markovsky, Y. Gofer, M. Schmidt and U. Heider, Electrochim. Acta, 2002, 47, 1423-1439.

17 G. E. Blomgren, J. Power Sources, 1999, 81, 112-118.

18 K. Xu, Chem. Rev., 2014, 114, 11503-11618.

19 K. Xu, Chem. Rev., 2004, 104, 4303-4418.

20 S. Bourlot, P. Blanchard and S. Robert, J. Power Sources, 2011, 196, 6841-6846.

21 M. Broussely, P. Biensan, F. Bonhomme, P. Blanchard, S. Herreyre, K. Nechev and R. Staniewicz, J. Power Sources, 2005, 146, 90-96.

22 S. Nowak and M. Winter, J. Anal. At. Spectrom., 2017, 32, 1833-1847.

23 M. Wohlfahrt-Mehrens, C. Vogler and J. Garche, J. Power Sources, 2004, 127, 58-64.

24 T. G. Zavalis, M. Klett, M. H. Kjell, M. Behm, R. W. Lindström and G. Lindbergh, Electrochim. Acta, 2013, 110, 335-348.

25 M. Grützke, V. Kraft, B. Hoffmann, S. Klamor, J. Diekmann, A. Kwade, M. Winter and S. Nowak, J. Power Sources, 2015, 273, 83-88.

26 P. Handel, G. Fauler, K. Kapper, M. Schmuck, C. Stangl, R. Fischer, F. Uhlig and S. Koller, J. Power Sources, 2014, 267, 255-259.

27 S. Nowak and M. Winter, J. Electrochem. Soc., 2015, 162, A2500-A2508.

28 C. Schultz, S. Vedder, B. Streipert, M. Winter and S. Nowak, RSC Adv., 2017, 7, 27853-27862.

29 C. Arbizzani, G. Gabrielli and M. Mastragostino, J. Power Sources, 2011, 196, 4801-4805.

30 T. Kawamura, S. Okada and J.-i. Yamaki, J. Power Sources, 2006, 156, 547-554.

31 X. Mönnighoff, P. Murmann, W. Weber, M. Winter and S. Nowak, Electrochim. Acta, 2017, 246, 1042-1051.

32 M. Pyschik, V. Kraft, S. Passerini, M. Winter and S. Nowak, Electrochim. Acta, 2014, 130, 426-430.

33 M. Pyschik, C. Schultz, S. Passerini, M. Winter and S. Nowak, Electrochim. Acta, 2015, 176, 1143-1152.

34 Y. P. Stenzel, F. Horsthemke, M. Winter and S. Nowak, Separations, 2019, 6, 26.

35 S. Wiemers-Meyer, S. Jeremias, M. Winter and S. Nowak, Electrochim. Acta, 2016, 222, 1267-1271.

36 S. Wiemers-Meyer, M. Winter and S. Nowak, Phys. Chem. Chem. Phys., 2016, 18, 26595-26601.

37 P. Verma, P. Maire and P. Novák, Electrochim. Acta, 2010, 55, 6332-6341.

38 M. Z. Winter, Phys. Chem., 2009, 223, 1395-1406.

39 E. Peled, J. Electrochem. Soc., 1979, 126, 2047-2051.

40 M. Evertz, J. Kasnatscheew, M. Winter and S. Nowak, Anal. Bioanal. Chem., 2018, 411(1), 277-285.

41 B. Vortmann-Westhoven, M. Winter and S. Nowak, J. Power Sources, 2017, 346, 63-70.

42 M. Diehl, M. Evertz, M. Winter and S. Nowak, RSC Adv., 2019, 9, 12055-12062.

43 M. Evertz, F. Horsthemke, J. Kasnatscheew, M. Börner, M. Winter and S. Nowak, J. Power Sources, 2016, 329, 364371. 
44 M. Evertz, C. Lürenbaum, B. Vortmann, M. Winter and S. Nowak, Spectrochim. Acta, Part B, 2015, 112, 34-39.

45 S. Nowak and M. Winter, Acc. Chem. Res., 2018, 51, 265-272. 46 T. Joshi, K. Eom, G. Yushin and T. F. Fuller, J. Electrochem. Soc., 2014, 161, A1915-A1921.

47 I. W. Seong, C. H. Hong, B. K. Kim and W. Y. Yoon, J. Power Sources, 2008, 178, 769-773.

48 N. Gunawardhana, N. Dimov, M. Sasidharan, G.-J. Park, H. Nakamura and M. Yoshio, Electrochem. Commun., 2011, 13, 1116-1118.

49 F. Sagane, R. Shimokawa, H. Sano, H. Sakaebe and Y. Iriyama, J. Power Sources, 2013, 225, 245-250.

50 F. Ding, W. Xu, G. L. Graff, J. Zhang, M. L. Sushko, X. Chen, Y. Shao, M. H. Engelhard, Z. Nie, J. Xiao, X. Liu, P. V. Sushko, J. Liu and J.-G. Zhang, J. Am. Chem. Soc., 2013, 135, 44504456.

51 D. Aurbach, B. Markovsky, A. Shechter, Y. Ein-Eli and H. Cohen, J. Electrochem. Soc., 1996, 143, 3809-3820.

52 S. Chandrashekar, N. M. Trease, H. J. Chang, L.-S. Du, C. P. Grey and A. Jerschow, Nat. Mater., 2012, 11, 311.

53 M. Börner, F. Horsthemke, F. Kollmer, S. Haseloff, A. Friesen, P. Niehoff, S. Nowak, M. Winter and F. M. Schappacher, J. Power Sources, 2016, 335, 45-55.

54 R. Moroni, M. Borner, L. Zielke, M. Schroeder, S. Nowak, M. Winter, I. Manke, R. Zengerle and S. Thiele, Sci. Rep., 2016, 6, 30109.
55 Y. Liu, Z. Hu, S. Gao, D. Günther, J. Xu, C. Gao and H. Chen, Chem. Geol., 2008, 257, 34-43.

56 J. Koch and D. Günther, Appl. Spectrosc., 2011, 65, 155A162A.

57 B. Rusk, Econ. Geol., 2009, 104, 601-602.

58 P. Harte, M. Evertz, T. Schwieters, M. Diehl, M. Winter and S. Nowak, Anal. Bioanal. Chem., 2019, 411, 581-589.

59 T. Schwieters, M. Evertz, A. Fengler, M. Börner, T. Dagger, Y. Stenzel, P. Harte, M. Winter and S. Nowak, J. Power Sources, 2018, 380, 194-201.

60 T. Schwieters, M. Evertz, M. Mense, M. Winter and S. Nowak, J. Power Sources, 2017, 356, 47-55.

61 J. S. Becker, Spectrochim. Acta, Part B, 2002, 57, 1805-1820.

62 A. A. Gorbatenko and E. I. Revina, Russ. Chem. Rev., 2015, 84, 1051.

63 E. R. Schenk and J. R. Almirall, Forensic Sci. Int., 2012, 217, 222-228.

64 G. Thyssen, M. Holtkamp, H. Kaulfürst-Soboll, C. Wehe, M. Sperling, A. von Schaewen and U. Karst, Metallomics, 2017, 9, 676-684.

65 S. Smetaczek, A. Wachter-Welzl, R. Wagner, D. Rettenwander, G. Amthauer, L. Andrejs, S. Taibl, A. Limbeck and J. Fleig, J. Mater. Chem. A, 2019, 7, 68186831.

66 M. Evertz, T. Schwieters, M. Borner, M. Winter and S. Nowak, J. Anal. At. Spectrom., 2017, 32, 1862-1867.

67 S. Flandrois and B. Simon, Carbon, 1999, 37, 165-180. 